\title{
Effects of Fly Ash on Properties of Concrete as Per Is: 10262-2009
}

\author{
Izhar Ahmed ${ }^{1}$ Dr S.S.Jamkar ${ }^{2}$ \\ ${ }^{1,2}$ Department of Applied Mechanics, Govt, Engg. college, Aurangabad.
}

\begin{abstract}
Properties of concrete depend up on properties of ingredients and their relative proportion. Due to addition of mineral as well as chemical admixture in concrete design of concrete mixes has become increasingly complex. BIS has rationalized concrete mix proportioning code in Dec 2009, which is used to design standard concrete mixes using both mineral as well as chemical admixtures. By considering the code, the present work deals with the development of fly ash based concrete mix proportion. This paper presents the results of an investigation dealing with Concrete cubes of $100 \mathrm{~mm}$ size, to replace 0\%, 5\%, 10\% and 15\% cement with fly ash. To cover a wide range of concrete mixes water cementitious material ratio (W/C) of $0.3,0.4$ and 0.5 were used for water content of $186 \mathrm{~kg} / \mathrm{m} 3,191.58 \mathrm{~kg} / \mathrm{m} 3$ and $197.16 \mathrm{~kg} / \mathrm{m} 3$ each. The effect of various parameters such as replacement of cement by fly ash, water to cementitious material ratio and water content is studied on fresh and hardened properties of concrete. The study mainly consisted of establishing relation between these parameters in the form of Graphs to specify proportioning of required fly ash based concrete. Both workability and strength aspects are considered.
\end{abstract}

Keywords: compressive strength, fly ash, Mix design, water content, W/C ratio

\section{Introduction:}

Concrete Mix proportioning refers to the process of determining the quantities of concrete ingredients using local materials, to achieve the specified characteristics of the concrete. A properly proportioned concrete mix should possess these qualities:

1. Acceptable workability of the freshly mixed concrete

2. Durability, strength, and uniform appearance of the hardened concrete

3. Economy

Understanding the basic principles of mixture design is as important as the actual calculations used to establish mix proportions. Only with proper selection of materials and mixture characteristics can the above qualities be obtained in concrete construction. (Abrams 1918, Hover 1998 and Shilstone 1990). ACI 211.1-91, DOE 1988 and IS 10262 are the procedures widely used for proportioning concrete mix. The IS 10262 is primarily based on the basic assumption that the compressive strength of concrete is governed generally, by the water-cement ratio. The recent development of using chemical and mineral admixtures in concrete has not alterted the applicability of the age-old Abram's water-cement ratio 'law', and the compressive strength of concrete is governed by the water-cementitious materials ratio used in concrete (S.C. Maiti 2006) . The cementitious materials include cement and mineral admixtures like flyash, ggbs and silica fume etc. The strength of the cementitious paste binder in concrete depends on the quality and quantity of the reacting paste components and on the degree to which the hydration reaction has progressed. Concrete becomes stronger with time as long as there is moisture and a favorable temperature available. Therefore, the strength at any particular age is both a function of the original water-cementitious material ratio and the degree to which the cementitious materials have hydrated.

Now a days design of concrete mixes has became increasingly complex with the addition of mineral as well as chemical admixture in concrete. There for BIS has rationalized concrete mix proportioning code in Dec 2009. This code is now in use to design concrete mixes using both mineral as well as chemical admixtures.

This paper investigates the effect of various parameters such as partial replacement of cement by fly ash, water to cementitious material ratio and water content are studied on fresh and hardened properties of concrete mix. The study mainly consisted of establishing relation between these parameters in the form of Graphs to specify proportioning of required fly ash based concrete. Both workability and strength aspects are considered.

\section{Selection Of Various Parameters:}

To proportioned Fly ash based concrete mixes were casted and tested in fresh and hardened state. Concrete cubes of $100 \mathrm{~mm}$ size were made for concrete mix proportioned to replace $0 \%, 5 \%, 10 \%$ and $15 \%$ cement with fly ash. To cover a wide range of concrete mixes water cementitious material ratio (W/C) of 0.3 , 0.4 and 0.5 were used for water content of $186 \mathrm{~kg} / \mathrm{m} 3,191.58 \mathrm{~kg} / \mathrm{m} 3$ and $197.16 \mathrm{~kg} / \mathrm{m} 3$ each. The dosages of super plasticizer keep constant throughout the work as $0.5 \%$ by mass of total cementitious material. In fresh 
state workability is measured in terms of slump and compacting factor. In hardened state, compressive strength is tested using CTM.

\section{Properties Of Fly Ash:}

Pozzocrete 60 is used as fly ash. P60 is obtained from Dirk India Pvt. Ltd. Maharashtra, India confirming to IS-3812-part I. physical properties of P60 is shown in Table 1.

Table 1: Typical physical properties of $\mathrm{P} 60$

\begin{tabular}{|l|l|}
\hline Presentation & Finely divided dry powder \\
\hline Colour & Light gray \\
\hline Bulk weight & 1.0 tonne/m3 \\
\hline Specific density & 2.3 \\
\hline Fineness & $<18 \%$ retained on $45 \mu$ sieve \\
\hline Particle shape & Spherical \\
\hline
\end{tabular}

\section{DESIGN STIPULATIONS FOR PROPORTIONING:}

a) Type of cement: OPC 43 grade, IS 8112 .

b) Nominal maximum size of aggregate: $20 \mathrm{~mm}$

c) Exposure condition: Moderate

d) Degree of supervision: Good

e) Type of aggregate: Crushed angular

f) Chemical admixture: S.P. $0.5 \%$ by mass of total cementitious material

\section{TEST DATA FOR MATERIALS:}

a) Cement used: OPC 43 grade.

b) Specific gravity of

1) Cement: 3.14

2) Coarse aggregate: 2.87

3) Fine aggregate: 2.67

c) Water absorption:

1) Coarse aggregate: $1.60 \%$

2) Fine aggregate: $1.25 \%$

d) Free moisture:

1) Coarse aggregate: NIL

2) Fine aggregate: NIL

e) Sieve analysis:

1) Coarse aggregate: Confirming to table 2 of IS 383.

2) Fine aggregate: confirming to Zone-I of IS 383.

\section{WORKABILITY:}

\section{Results And Discussion:}

To analyse the behavior of concrete in fresh state, three different water content i.e. $186 \mathrm{~kg} / \mathrm{m} 3,191.58$ $\mathrm{kg} / \mathrm{m} 3$ and $197.16 \mathrm{~kg} / \mathrm{m} 3$ were selected for each W/C ratio. Graph 1 and Graph 2 shows the behavior of workability in terms of slump, for W/C ratio of 0.4 and 0.5 .

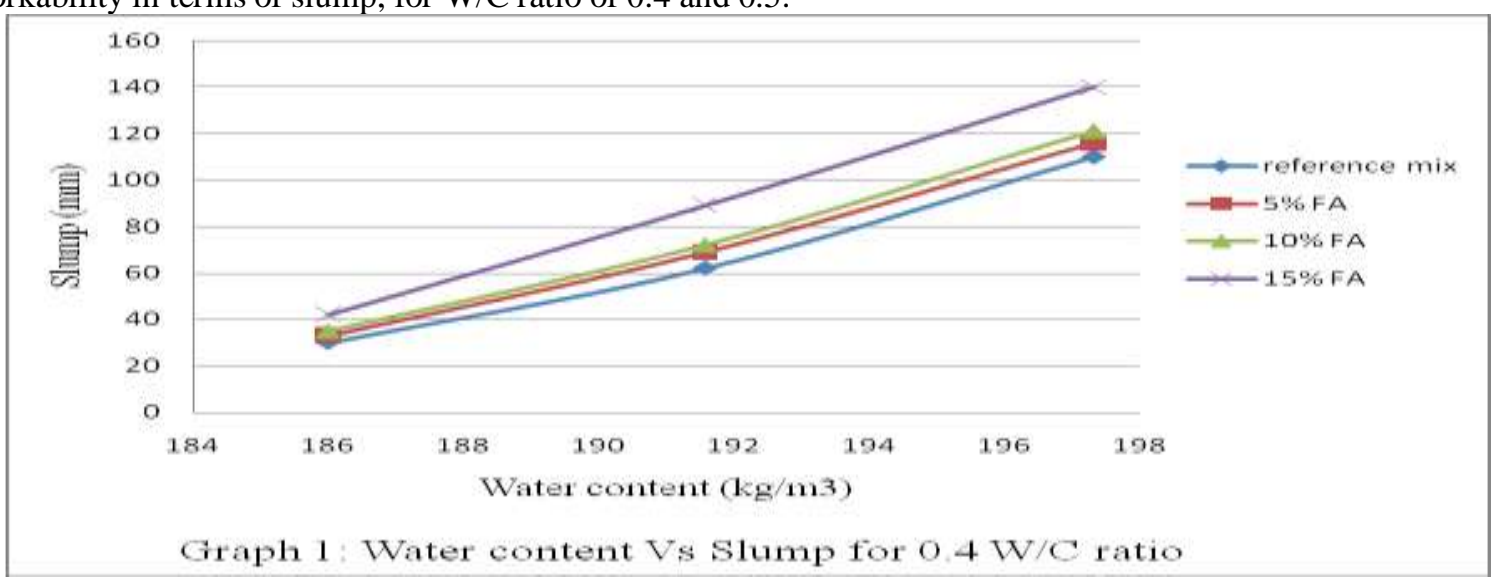




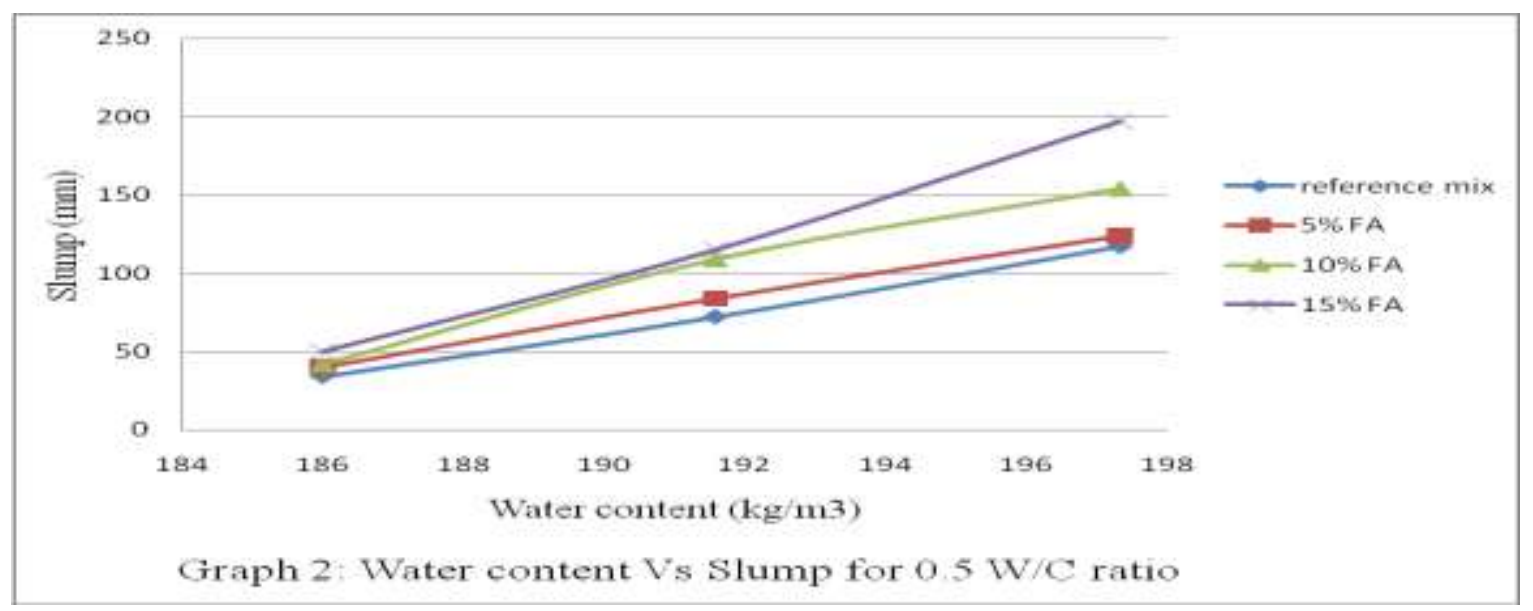

It is observed that for a given W/C ratio and for given water content, addition of fly ash increases the workability. Workability goes on increasing with increase in percentage of fly ash from 5\% to $15 \%$. This trend is consistent for W/C ratio of 0.4 and 0.5 . For W/C ratio of 0.3 , mixes with and without fly ash is very low workable as per IS 456-2000. Hence a higher dosage of superplasticizer (SP) is required to achieve desired workability. The workability of fly ash based concrete is improved in following ways: a) As fly ash has lower specific weight, the resultant cement paste results in a bigger volume of cementing materials which is easy to handle and compacted.(b) The very fine particles existing in fly ash are attached by cement particles, forming a structure similar to a ball bearing, which reduces friction and improves workability.(c) The perfect spherical shaped fly ash particles are not able to interlock between themselves or with the cement particles, providing lubricating effect to fresh binder matrix.(Mukund Joshi). To achieve desired workability for a particular water cement ratio, water content can be selected from Graph 1 and Graph 2, for different percentages of fly ash.

COMPRESSIVE STRENGTH: The results for compressive strength for 7 days, 28 days and 56 days, obtained from the experimental investigation are represented graphically in Graph 3, Graph 4 and Graph 5 respectively.
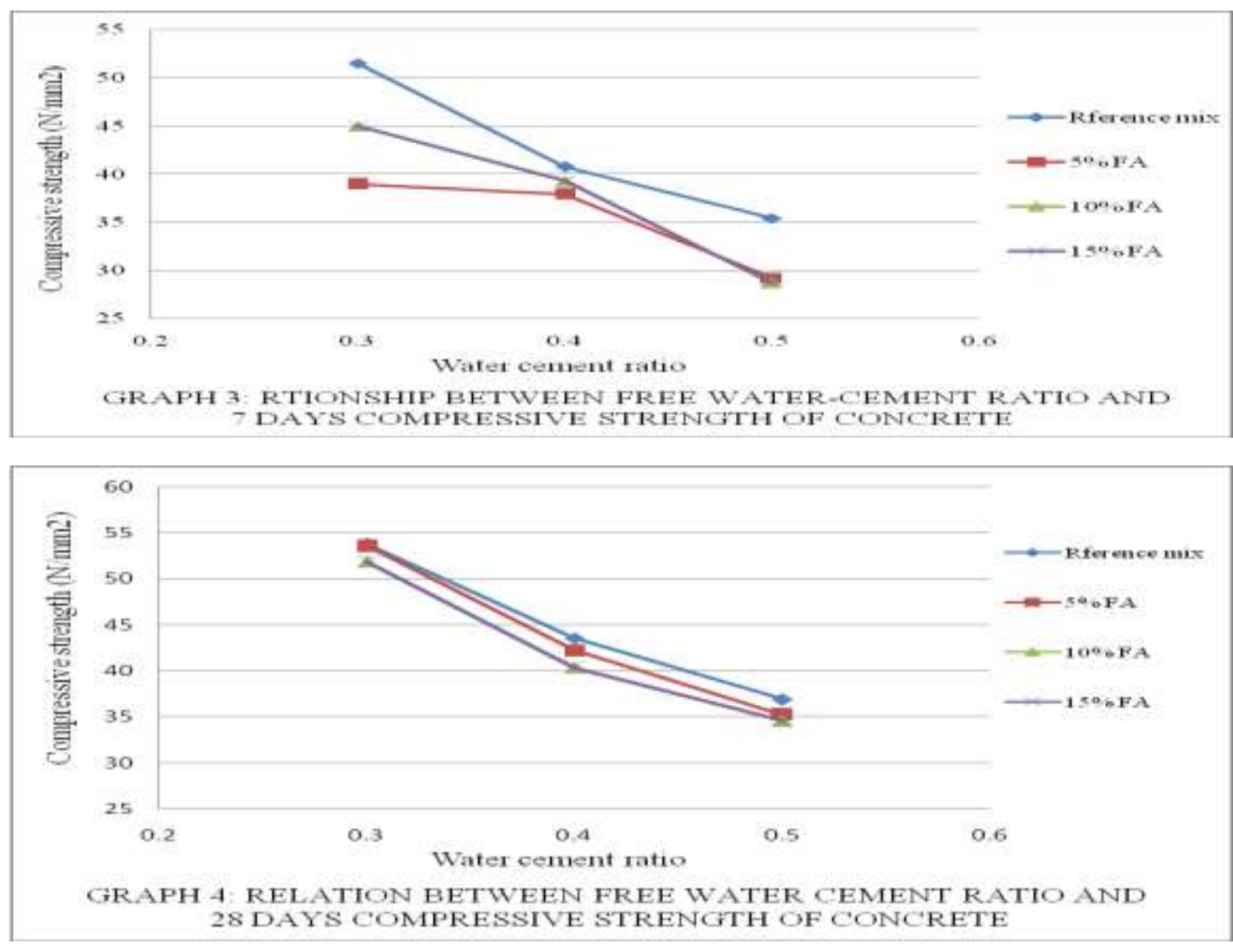


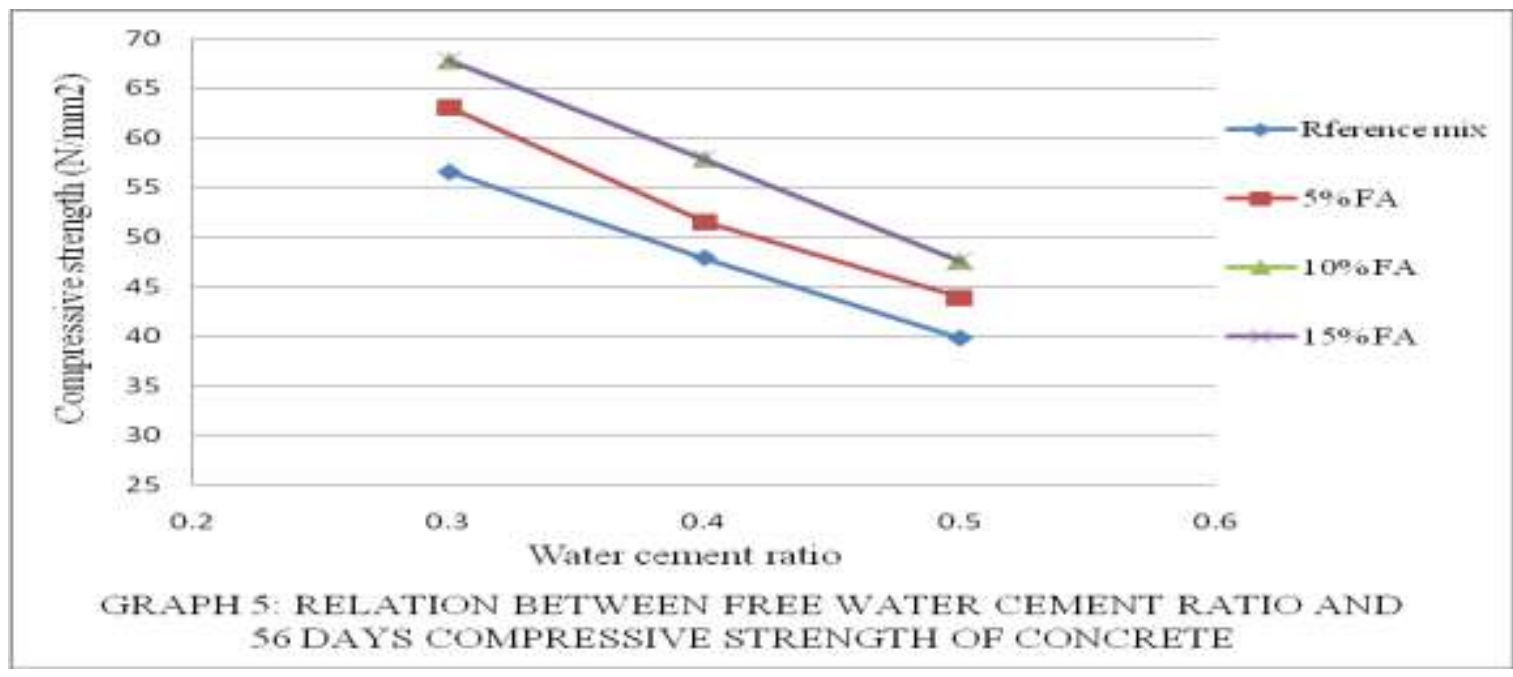

It is seen from the graph, the mixes containing $5 \%, 10 \%$ and $15 \%$ fly ash, gain compressive strength more slowly as compare to reference mix ( $0 \%$ fly ash) up to 28 days. Beyond 28 days concrete containing fly ash will ultimately exceeds the strength.

V. Effect of Age On Compressive Strength:

From the above Graphs it is observed that for all W/C ratios and percentage replacement of fly ash with OPC, increase in compressive strength tremendously from 7 to 56 days. Graph 6, Graph 7 and Graph 8 shows the relation between age of concrete and compressive strength in Mpa for 0.3, 0.4 and $0.5 \mathrm{~W} / \mathrm{C}$ ratio respectively.
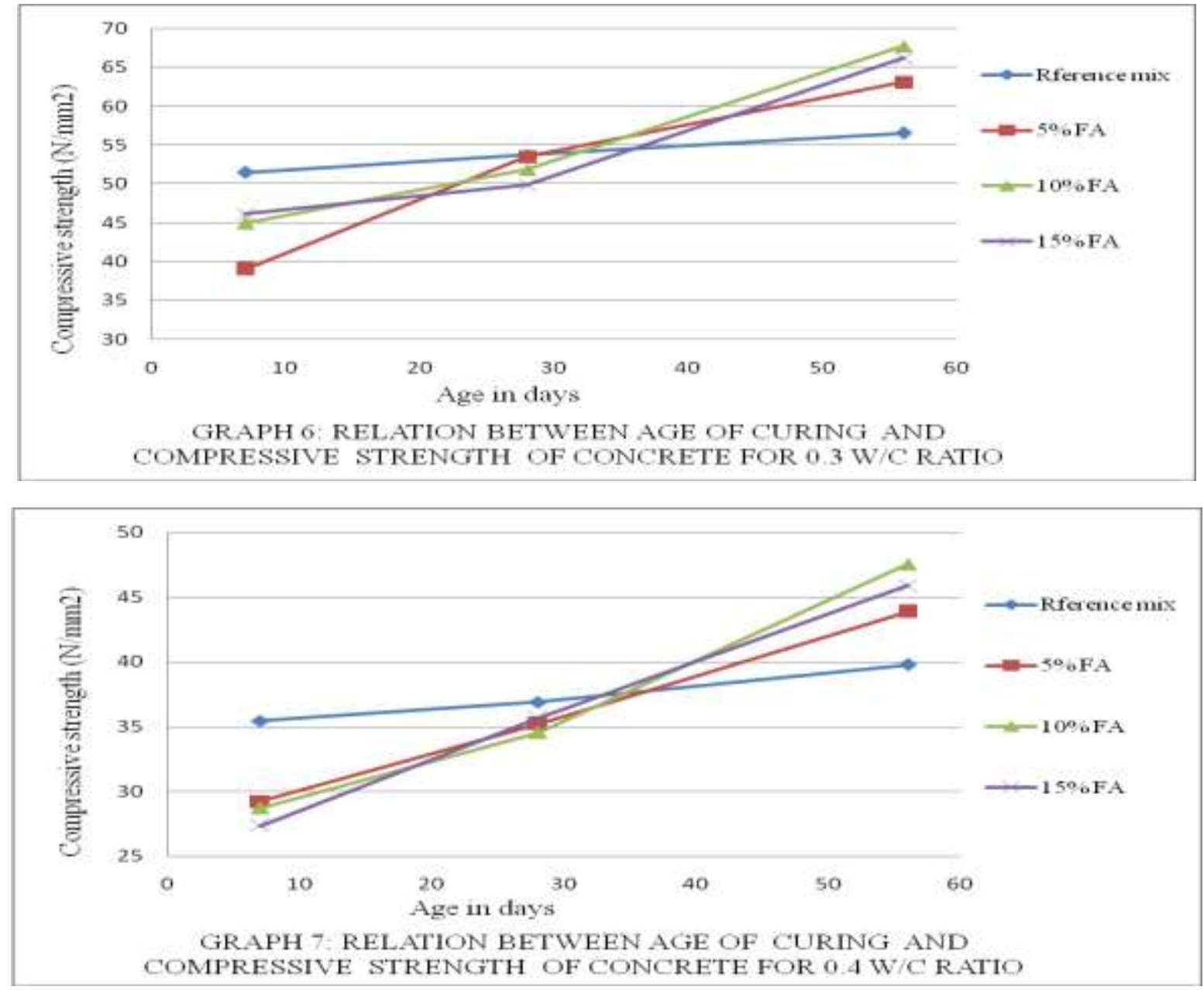


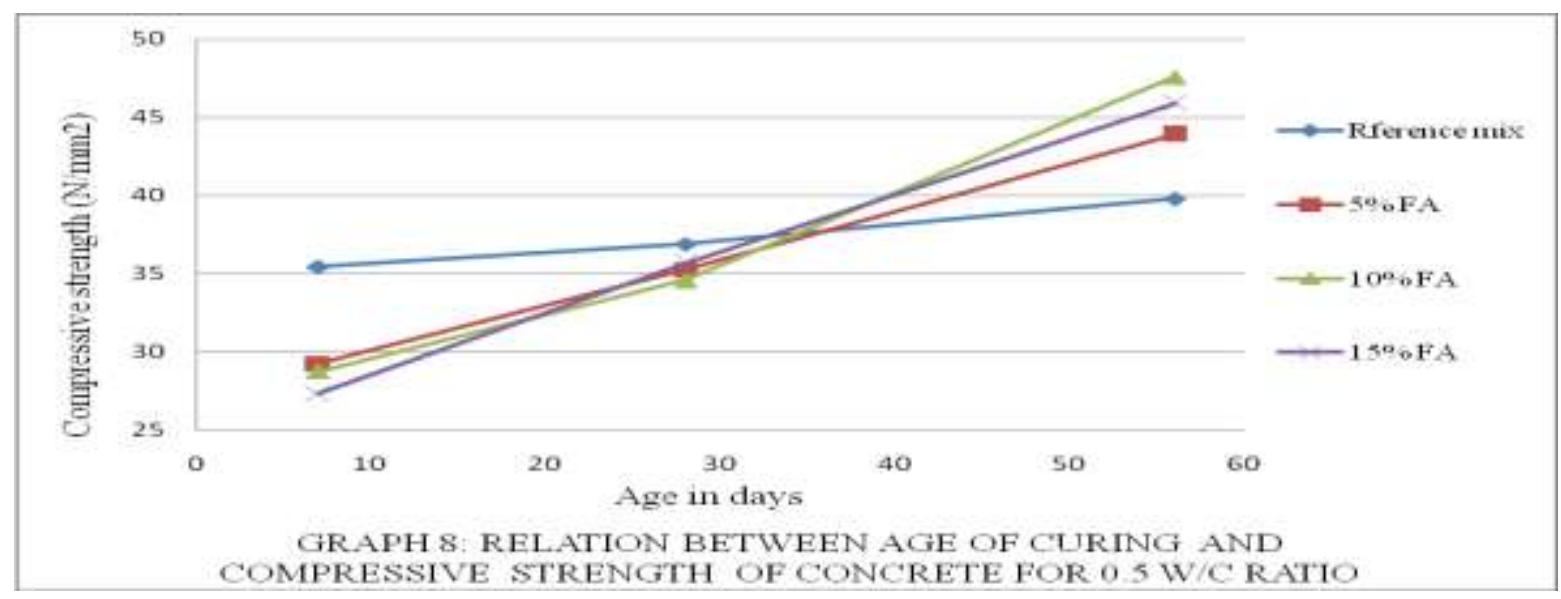

It is observed from the above Graph for all W/C ratio considered, concrete containing fly ash has very low early age compressive strength i.e. at 7 days. But at the age of 28 days the strength is increased which is nearly equals to reference concrete. Observations of 56 days compressive strength shows much better results than reference mix. Concrete containing $10 \%$ replacement of fly ash by weight of cement gives better results than $5 \%$ and $15 \%$ replacement.

\section{Conclusion:}

Following conclusions are drawn based on the experimental results.

I. Fly ash based concrete mix shows better results of workability as compare to reference concrete.

II. For all W/C ratio considered and percentage replacement of fly ash by OPC, compressive strength increases tremendously from 7 to 56 days.

III. Relationships between water-cementitious material ratio and 28-day compressive strength of concrete containing fly ash are almost same as reference concrete.

IV. 56 days compressive strength of concrete containing fly ash shows much better results than reference mix.

V. Concrete containing $10 \%$ replacement of fly ash by weight of cement gives better results than $5 \%$ and $15 \%$ replacement.

VI. To achieve desired workability, water content for w/c ratio of 0.4 and 0.5 can be selected with the help of Graph 1 and Graph 2 respectively.

VII. W/C ratio can be selected from the relationship between water cement ratio and 28 days compressive strength of concrete shown in Graph 4 for different percentages of fly ash.

VIII. By knowing water content and W/C ratio, cementitious material content can be calculated.

\section{References}

[1]. Indian standard concrete mix proportioning - Guidelines (First revision) IS: 10262-2009, Bureau of India Standard, New Delhi, India.

[2]. Code of practice for plain and reinforced concrete (fourth edition) IS: 456-2000, Bureau of India Standard, New Delhi.

[3]. M.C. Nataraja and Lelin Das, "Concrete mix proportioning as per IS: 10262-2009 Comparison with IS: 10262-1982 and ACI 211.1-91.” THE INDIAN CONCRETE JOURNAL, September 2010.

[4]. S.C. Maiti, Raj K. Agarwal and Rajeeb Kumar, "Concrete mix proportioning” THE INDIAN CONCRETE JOURNAL, December 2006.

[5]. Durocrete Engineering services pvt. Lit. "Mix Design Manual."

[6]. M.C. Nataraja and Lelin Das, "Some studies on concrete mix proportioning following IS 10262-2009." THE INDIAN CONCRETE JOURNAL, January 2011.

[7]. Mukund joshi, "performance of fly ash and understanding IS: 3812-2003(part-1)," CE and CR, April 2005, pp. 45-48.

[8]. Abrams, D. A., Design of Concrete Mixtures, Lewis Institute, Structural Materials Research Laboratory, Bulletin No.1, PCA LS001, Chicago, 1918.

[9]. Shilstone, James M., Sr., "Concrete Mixture Optimization," Concrete International, American Concrete Institute, Farmington Hills, Michigan, June 1990.

[10]. IS 383, "Specifications for Coarse and Fine Aggregates from Natural Source of Concrete," Bureau of Indian standard New Delhi, 1982. 